\title{
EN TORNO AL ESTUDIO HISPÁNICO DE LA MICROFICCIÓN CONTEMPORÁNEA: OBJECIONES A LA CONSIDERACIÓN DEL MICRORRELATO COMO TEXTO NARRATIVO ${ }^{1}$
}

\author{
AROUND THE HISPANIC STUDY OF CONTEMPORARY FLASH \\ FICTION: OBJETIONS TO THE CONSIDERATION OF MICRO- \\ STORY AS A NARRATIVE TEXT
}

\begin{abstract}
Jorge GÓMEZ VÁZQUEZ
Universidad Nacional de Educación a Distancia (UNED)

jorgegrual@hotmail.com
\end{abstract}

Resumen: En este estudio exponemos ciertas objeciones sobre la concepción y definición del microrrelato como texto narrativo, pues la particular narratividad del fenómeno literario aludido, también denominado minicuento o minificción, no resulta acorde con la delimitación de texto narrativo, tanto por los frecuentes casos de elisión parcial o completa de la secuencia textual narrativa, por ejemplo, como por los constantes casos de hibridez o mixtura narrativa entremezclada de elementos no narrativos. En este sentido, preferimos la denominación de microficción por resultar un término más abarcador, distintivo y adecuado para este singular género estudiado.

Palabras clave: Mini/Microficción. Mini/Microrrelato. Mini/Microcuento. Texto narrativo. Narratividad.

1.Este estudio se ha realizado en el marco de los estudios de Doctorado de la UNED, dentro del Programa de Doctorado en "Filología. Estudios lingüísticos y literarios: teoría y aplicaciones". 
Abstract: In this study, we expose certain objections about the conception and definition of the micro-story as narrative text, because the particular narrativity of the literary phenomenon mentioned, also called micro-tale or micro-fiction, does not agree with the delimitation of narrative text: as much for the frequent cases of partial or complete elision of the narrative textual sequence, for example, as by the constant hybridity or mixed narrative mixture of non-narrative elements. In this sense, we prefer the definition microfiction to be a more comprehensive, distinctive and appropriate term for this unique genre studied.

Key Words: Mini/Micro-fiction. Mini/Micro-story. Mini/Micro-tale. Narrative text. Narrativity.

\section{PREVIAS ACLARACIONES SOBRE NOMENCLATURA Y PERSPECTIVAS NARRATIVISTAS EN LA MICROFICCIÓN}

En general, los términos mini/microcuento, mini/microficción y mini/microrrelato suelen aludir a un mismo fenómeno literario específico, en torno al cual se han utilizado diversas y creativas denominaciones, aunque en el conjunto de los estudios sistemáticos, iniciados a partir de los años $80^{2}$, sobresalen - a veces con ciertos matices diferencialesaquellos tres señalados términos más especializados: minicuento, minificción y microrrelato, cuyos dos últimos tecnicismos son los que han resultado preferentes dentro del marco teórico de los estudios actuales y colectivos hispánicos. Por otro lado, dentro de este marco teórico conjunto, se han propuesto diferentes postulados en torno a la definición, delimitación y caracterización de tal objeto de estudio microficcional. Alrededor de algunos de estos postulados, vamos a abordar y objetar ciertas perspectivas narrativistas en las que se suele concebir y definir el microrrelato como texto narrativo. Asimismo, dentro de algunas de estas perspectivas, se ha entendido y definido la minificción como un término hiperónimo que incluiría a todos los microtextos ficcionales representados por diversas especies, géneros o categorías/formas cortas literarias, entre

2. La crítica especializada ha reconocido en un primer artículo publicado de Dolores M. Koch (1981), titulado "El micro-relato en México: Torri, Arreola, Monterroso y Avilés Fabila", el arranque de los estudios sistemáticos sobre minificción. 
los cuales se hallaría como hipónimo el microrrelato (cf. Andrés-Suárez, 2008: 20-21; Lagmanovich, 2006a: 23-31). En ambos casos, diferimos de tales postulados y definiciones, pues, en primer lugar, no reconocemos la particular concepción del microrrelato (sinónimo para nosotros de minificción) como texto pura o solamente narrativo, y, en segundo lugar, tampoco concebimos la minificción como tal supuesto término hiperónimo, principalmente porque esta denominación no representa a otros géneros (o categorías/formas) breves literarios, ya sean estos antiguos (fábulas, parábolas, casos, etc.) o modernos (tal como, por ejemplo, el poema en prosa). Por otra parte, el término minificción se difundió a partir de 1970 en uno de los principales espacios fundacionales de consolidación y proyección genérica del fenómeno: la emblemática e internacional revista mexicana $\mathrm{El} \mathrm{Cuento}^{3}$, dirigida por Edmundo Valadés. El distintivo término difundido en la revista de Valadés aportó una denominación acertada y precisa respecto al corpus proyectado y promocionado - a través también de su periódico concurso precursor del género- desde algunas secciones resaltadas en su revista, entre las cuales destaca la ejemplar sección permanente de "Caja de sorpresas", en donde se conjugaba la recopilación de evidentes minificciones mundiales del siglo XIX y XX, el rescate recontextualizador de microtextos (mayormente micronarrativos) de todas las épocas y lugares y la cocreación microficcional por medio de diversas operaciones hacedoras de minificciones, tal y como ya había establecido Borges en colaboración con Bioy ${ }^{4}$. Alrededor de esta proyección, tampoco se puede obviar el gran impulso que supuso esta revista para la progresiva conciencia genérica de la minificción, en torno a la cual se difundieron

3. La palabra minificción aparece impresa en el sumario del ejemplar n. ${ }^{\circ} 40$, correspondiente a enerofebrero de 1970, de El Cuento. Revista de la imaginación, cuyo ejemplar puede verse en http://www.elcuentorevistadeimaginacion.org/indexcuento.php [20/05/2017].

4. Tales influyentes operaciones hacedoras de microficciones fueron practicadas por Borges, en colaboración con Bioy, en su sección microficcional "Museo", cuya célebre sección apareció primero en los tres únicos números de la revista Destiempo (1936-1937) y, ya desarrollada y perfeccionada, en la revista Los Anales de Buenos Aires (n. ${ }^{\circ}$ 3-11, de 1946). Estas operaciones perfeccionadas reaparecerán luego en célebres antologías de Borges en colaboración (con Bioy y/o con otros colaboradores). Así, por ejemplo, en la segunda edición de la Antología de la literatura fantástica ([1940] 1965), de Borges, Bioy y Ocampo, se incluirán títulos espurios a los recortados textos hiperbreves ya publicados en la primera edición, cuyas intitulaciones espurias ya habían practicado Borges y Bioy en la sección "Museo" de 1946. Por otra parte, las diversas operaciones microficcionales de recortes, intitulaciones espurias, recontextualizaciones microtextuales, etc., unido a la recopilación de específicas minificciones contemporáneas, las ejecutará Borges (en colaboración o en solitario) en diversas antologías posteriores al "Museo" de 1946. Asimismo, todas estas operaciones borgianas (y bioyanas) influirán en posteriores y precursoras revistas y antologías hispánicas de minificción. 
otras denominaciones alusivas a tales producciones, pero menos distintivas por su relación denominativa con el cuento, entre la cuales apuntamos solo la más general, extendida y problemática: cuento/relato breve/corto (así como el de micro/minicuento). Por otra parte, Dolores Koch procuró también distinguir —apoyándose en previas distinciones y puntualizaciones ya señaladas por Luis Leal ([1966] 1971) — entre lo que consideró como un fenómeno más narrativo y relacionado o ligado con el cuento, es decir el cuento muy breve (o minicuento), y aquello otro que observaba Koch, en torno a una particular producción microficcional desarrollada por destacados escritores hispanoamericanos (Julio Torri, Juan José Arreola, Augusto Monterroso, René Avilés Fabila, Jorge Luis Borges, Julio Cortázar, Marco Denevi, Virgilio Piñero, etc.), como un fenómeno literario no tan narrativo y más distintivo respecto al género cuento: el micro-relato, el cual, según lo solía definir Koch, "participa de la naturaleza de la narrativa, el ensayo y el poema en prosa" (1986: 9). Posteriormente, en torno a la concepción general del fenómeno microficcional, ya sea denominado y estudiado como microrrelato o minificción, las distinciones de Koch entre minicuento y micro-relato volverán a quedar subsumidas tal vez por simplificar las dificultades teóricas que conllevan tales matices distintivos - en aquellos dos términos más preferentes en los estudios sistemáticos actuales sobre tal fenómeno literario (más allá de ciertas divergencias o postulados particulares). Ahora bien, dicho esto, nuestra mayor preferencia por el término microficción, en lugar de microrrelato, se justifica, en buena medida, por las implicaciones que conllevan las objeciones que planteamos y desarrollamos en este estudio, a través del cual se podrán observar algunos de los problemas y delimitaciones que plantean ciertos postulados más narrativistas, especialmente agudizados por destacados investigadores españoles, que suelen concebir la narratividad del microrrelato en base a su textualidad narrativa. Nosotros, en cambio — adelantamos aquí-, concebimos y definimos el fenómeno genérico de la microficción contemporánea (denominada microrrelato, minificción o minicuento) como un microtexto literario autónomo de ficcionalidad narrativizadora gobernada por la elipsis. Es decir, el común denominador genérico de este corpus microtextual está en su carácter ficcional de índole narrativizador o narrabilizador, y no en que el texto sea o deba ser narrativo, ya que, tal como se verá, no solo algunos de los necesarios elementos de la secuencia narrativa textual pueden estar elididos, sino que, más aún, la 
secuencia textual narrativa puede estar completamente elidida. Asimismo, la narratividad prosística del específico fenómeno literario aludido puede conllevar cierta hibridez o mixtura de elementos no narrativos, tal como ya señalaba Dolores Koch respecto a su específica distinción del micro-relato, lo cual, pensamos, está relacionado con el desarrollo formal y sustancial de su diversa genealogía y con su denominado carácter proteico, entre otras posibles y variadas causas.

\section{ACERCA DE LA LIMITADORA DEFINICIÓN DEL MICRORRELATO COMO TEXTO NARRATIVO}

Vamos a señalar ahora lo indicado por Domingo Ródenas de Moya en torno a lo que suele concebirse, desde ciertos postulados narrativistas, por microrrelato, entendido este como fenómeno literario microtextual narrativo, $y$, por ende, texto narrativo definido como tal desde perspectivas narratológicas. Así pues, dice Ródenas lo siguiente:

Utilicemos microrrelato, minicuento [...] o cualquier denominación, el objeto al que aludimos es un texto narrativo muy breve con valor estético. Ello lo sitúa en la intersección de tres ámbitos: la textualidad narrativa, la microtextualidad y la literariedad [...]. Para que un texto literario pueda ser considerado microrrelato sólo debe cumplir dos condiciones: brevedad y narratividad. Determinar cómo se objetiva esta segunda condición es bien sencillo gracias, por un lado, a las aportaciones de la narratología y, por otro, a los estudios de tipología textual en el marco disciplinario del análisis del discurso. De acuerdo, por ejemplo, con Jean-Michel Adam, la narración es un modo de organización del discurso que implica cinco factores como constituyentes estructurales: la temporalidad como sucesión de acontecimientos; unidad temática, garantizada por ejemplo por un sujeto actor (o actante); la transformación de una estado inicial o de partida en otro distinto y final; unidad de acción que integre los acontecimientos en un proceso coherente; y la causalidad que permita al lector reconstruir nexos causales en una 
virtual intriga. El microrrelato, pues, debe presentar estos requisitos o, de lo contrario, no puede ser considerado texto narrativo (Ródenas, 2007: 70-71).

Si entendemos en esta definición de microrrelato el componente de ficción integrado ya en la aludida literariedad (Garrido Domínguez, 1993: 29), y profundizamos algo más en esa imprecisa brevedad ${ }^{5}$, estaremos de acuerdo con Ródenas en todo lo señalado, salvo en uno de los tres puntos fundamentales: lo seguido por Ródenas para definir un texto como narrativo, es decir: "la descripción de la secuencia narrativa que elabora Jean-Michel Adam, [en] Les textes: types et protoypes. Récit, description, argumentation, explication et dialogye, París, Nathan, 1992" (Ródenas,

5. En este sentido, si consideramos los principales espacios fundacionales de proyección genérica de la microficción, tales como precursoras revistas y antologías hispánicas, se comprobará que la extensión más recurrente y marcada de la minificción allí difundida no suele exceder la hoja impresa y las 300 palabras. En torno a tal extensión microtextual, se establece, pues, el mayoritario corpus de minificciones recopiladas (y resignificadas) en las consideradas iniciadoras antologías hispánicas del género, tales como, por ejemplo, Cuentos breves y extraordinarios (1955; $2^{\mathrm{a}}$ edición ampliada en 1973) y Libro del cielo y del infierno (1960), ambas elaboradas por Jorge Luis Borges y Adolfo Bioy Casares; El libro de la imaginación (1970; $2^{\text {a }}$ edición aumentada en 1976), de Edmundo Valadés; Los primeros cuentos del mundo (1977), de Enrique Anderson Imbert; Brevísima relación del cuento breve de Chile (1989) y Brevísima relación. Antología del micro-cuento hispanoamericano (1990), ambas compiladas por Juan Armando Epple; La mano de la hormiga... (1990), de Antonio Fernández Ferrer; Antología del cuento corto colombiano (1994), de Guillermo Bustamante Zamudio y Harold Kremer, etc. Respecto a los términos minificción y microrrelato, comenzarán a difundirse en los títulos de antologías publicadas a partir del último lustro del siglo XX, tal como se comprueba ya en las siguientes antologías: Dos veces cuentos. Antología de microrrelatos (1998), de Joseluís González; La minificción en Colombia. Antología (2002), de Henry González Martínez; La minificción en México. 50 textos breves (2002) y Minificción mexicana (2003), ambas de Lauro Zavala; La minificción en Panamá. Breve antología del cuento breve en Panamá (2003), de Enrique Jaramillo Levi, etc. Por otro lado, la extensión microtextual mencionada será, de igual manera, la más recurrente y marcada en las relevantes secciones de minificción difundidas en precursoras revistas hispanoamericanas, tal y como sucede, por ejemplo, en las secciones de "Caja de sorpresas" $\mathrm{y}$, posteriormente, en las secciones del correo y concurso de minificciones — precursor concurso del género en donde ya se establece la extensión microtextual máxima en torno a las 250 palabras - de la revista El Cuento (1964-1999), refundada por Valadés (México, 1915-1994), cuya difusión y promoción minificcional repercutirá sobre otras revistas, entre las cuales cabe destacar la colombiana Ekuóreo, Revista de minicuentos (1980-1984; 1992), dirigida por Zamudio y Kremer, y la argentina Puro Cuento (1986-1992), dirigida por Mempo Giardinelli. Pero más allá de tales espacios fundacionales de proyección genérica de la minificción, la caracterizadora hiperbrevedad de la microficción (mayormente hispánica) proviene, sustancialmente, de su llamado carácter proteico en relación con el extenso y perenne repertorio microtextual (especialmente micronarrativo) de la tradición oral y literaria, ya sea a través de la adopción formal, pero disfuncional, de categorías/formas cortas arcaicas y tradicionales, tales como, por ejemplo, el conjunto de los llamados géneros gnómicos, ya sea a través de esferas de producción creacional más relacionadas con la concepción tradicional de la escritura de fragmentos o aforismos, o ya a través de ciertas adaptaciones y derivaciones modernistas hispánicas del poema en prosa, entre otras variadas hibridaciones genéricas y revestimientos proteicos, algunos de los cuales implican también múltiples microformas transliterarias. En torno a todo esto y a su general intensificación de la elipsis, la compleja y particular narratividad del microrrelato o minificción resulta precaria o problemática en su definición pretendida de texto narrativo. 
2007: 71).

Creemos que este tipo de asunciones narratológicas son las que han supuesto o suponen un escollo para comprender y abarcar bien la particular y distintiva fenomenología de la narratividad del microrrelato. No estamos diciendo aquí que cierta secuencia narrativa no se produzca (secuencia que, por otra parte, otros autores suelen simplificar), sino que en el fenómeno del microrrelato no siempre se produce de una forma textualmente evidente (hay también casos, por otro lado, de una narratividad en torno a conceptos o ideas), ni siempre se ofrece textualmente tal secuencia, ya que pueden aparecer elididos algunos factores básicos y constitutivos de tal secuencia narrativa, o, más aún, hay ciertos casos de extrema elisión de tal secuencia narrativa. Parte de lo que aquí señalamos ya lo indicó Juan Armando Epple en el prólogo de su antología de 1990, en donde apuntaba a esa secuencia narrativa - aquí más simplificada - que debe tener el microrrelato, pero considerando también lo siguiente:

lo que distingue a estos textos como [micro-]relatos es la existencia de una situación narrativa única formulada en un espacio imaginario y en su decurso temporal, aunque en algunos elementos de esta tríada (acción, espacio, tiempo) estén simplemente sugeridos. [...] El dinosaurio es un ejemplo propicio: "Cuando despertó, el dinosaurio todavía estaba alli". Aquí la narración está reducida al mínimo posible, a un eje clave de la tensión narrativa, mostrando el quiebre de las fronteras entre la realidad y el sueño, la súbita interrupción de lo fantástico. Pero en ésta hay un decurso temporal (fijado en los verbos) y una referencia a la situación espacial ("alli", el lugar donde ocurre la experiencia). Hay otros [micro-]relatos donde no están explicitados todos los elementos básicos que concurren a particularizar el estrato del mundo narrado (algo que hace o le ocurre a alguien en algún lugar), pero donde hay al menos uno de ellos sosteniendo la concreción de lo narrado, convocando o aludiendo implícitamente a los otros para consolidar su connotación de sentido (Epple, [1990] 1999: 20 [la redonda es nuestra]). 
Este tipo de microrrelatos en los que no se explicita la secuencia narrativa íntegra son abundantes y, lógicamente, seguirán produciéndose en abundancia dentro de la fenomenología característica del microrrelato o minificción. La perspectiva más narrativista del microrrelato, basada en la concepción de la secuencia textual narrativa, resulta precaria y no puede abarcarlos ni definirlos, solo ignorarlos o emparentarlos con otras especies o categorías literarias hiperbreves, lo cual, desde nuestro punto de vista, supone un craso error, pues son fenómenos evidentes de la microficción (precisamente son los fenómenos más característicos dentro del desarrollo particular del fenómeno literario denominado minicuento, minificción o microrrelato). Para indicarlos como tales microrrelatos, vamos a recurrir a un destacado investigador de perspectivas narrativistas, tal y como el mismo David Lagmanovich concibe su estudio sobre El microrrelato. Teoría e historia (2006a: 30). Así pues, se podrán encontrar ejemplos de este tipo de microrrelatos - señalados como tales por el propio Lagmanovich-en su relevante y canónico estudio citado, en donde dedica todo un apartado a "La extrema brevedad: microrrelatos de una o dos líneas" (2006a: 49-83), y, más concretamente, en el corpus de 46 microrrelatos de la "sección C: menos de 20 palabras" (69-78). Por otra parte, los problemas planteados por Lagmanovich al final de tal apartado proceden de cierta asunción previa del microrrelato como texto narrativo. Sin embargo, el microrrelato o minificción, tal como procuraremos mostrar, no se puede definir como un fenómeno de textualidad narrativa tal cual, ya que no todos los microrrelatos reflejan su secuencia narrativa en el texto, así como tampoco se puede concebir su narratividad prosística como pura, pues en abundantes casos, muy evidentes y consignados como microrrelatos, la narratividad conlleva hibridación de elementos más poéticos o especulativos ${ }^{7}$.

No obstante, según habíamos adelantado en la introducción, podríamos solventar tales problemas al definir el fenómeno de la microficción contemporánea (denominada minicuento, minificción o microrrelato)

6. El citado apartado de Lagmanovich, titulado "La extrema brevedad: microrrelatos de una o dos líneas", también se publicó en el n. 32 de la revista Espéculo (Lagmanovich, 2006b), pero aquí se incluyeron nueve microrrelatos más dentro de la mencionada "sección C".

7. No vamos a detenernos ahora en esto último, solo piénsese, entre otro muchos y posibles ejemplos, en la minificción de Arreola titulada "Camélidos", de prosa poética y de narratividad muy descriptiva, o en la especulativa minificción de Borges titulada "Argumentum ornithologicum". Ambas microficciones las incluyó Lagmanovich en la sección "Los clásicos del microrrelato" de su antología hispánica del género, titulada $L a$ otra mirada. Antología del microrrelato hispánico (cf. Lagmanovich, 2005: 70 y 76). 
como un microtexto literario autónomo de ficcionalidad narrativizadora gobernada por la elipsis. Así pues, en esta básica, matizada e integral definición genérica del fenómeno literario microficcional, también estarán contempladas aquellas producciones más hiperbreves y problemáticas desde una definición literal del microrrelato como texto narrativo, en las cuales se produce en lo elidido (es decir, en lo no explicitado textualmente) el desencadenamiento de una parte (o del todo) de la secuencia narrativa, pero desvelada aquí por índices de intenciones narrativizadoras en la creación proyectiva de situaciones (mundos) ficcionales.

\subsection{Algunos ejemplos de microrrelatos de textualidad narrativa difusa}

A continuación, recogeremos algunos ejemplos de microrrelatos en los que no parece desarrollarse, definirse o plasmarse bien la secuencia textual narrativa, o bien, tal como señalaba Epple, no aparecen explicitados todos los elementos básicos narrativos. Para ello, nos serviremos de algunos de los microrrelatos recopilados por Lagmanovich en la citada "sección C" de su libro, teniendo en cuenta que la mayoría de estos, a su vez, fueron y han sido recogidos en otras tantas antologías hispánicas de minificción. Por otra parte, prescindiremos aquí de todos aquellos microrrelatos relacionados intertextualmente con "El dinosaurio", ya que suelen repetir ese esquema narrativo analizado por Epple, pero también por no persistir en esta temática tan archiconocida y versionada, aunque no faltan creaciones más innovadoras o meritorias alrededor de tales homenajes paródicos a este celebérrimo microrrelato ${ }^{8}$. Dicho esto, pasamos a transcribir algunos de los microrrelatos recogidos por Lagmnovich en su "sección C":

66. Eugenio Mandrini (Argentina): "Prueba de vuelo"

Si evaporada el agua el nadador todavía se sostiene, no cabe duda: es un ángel.

68. Marco Denevi (Argentina): "Don Juan y las mujeres" A ninguna le disgusta tener antecesoras a condición de no

8. Respecto a esta legión de monterrosaurios, remitimos al interesante estudio y antología de Lauro Zavala: El dinosaurio anotado. Edición crítica de "El dinosaurio" de Augusto Monterroso (2002).

9. Indicaremos con un asterisco aquellos microrrelatos que ya habían sido recogidos en la citada antología de Lagmanovich (2005). 
tener sucesoras.

70. Juan José Arreola (México): "De escaquística”

La presión ejercida sobre una casilla se propaga en toda la superficie del tablero.

79. Edmundo Valadés (México): "La búsqueda”*

Esas sirenas enloquecidas que aúllan recorriendo la ciudad en busca de Ulises.

81. Marco Denevi (Argentina): “Justificación de la mujer de Putifar"**

¡Qué destino: Putifar, eunuco, y José, casto!

82. Guillermo Samperio (México): "Bebo tu boca”*

Cuando beso tus labios de agua, nunca son los mismos.

84. David Lagmanovich (Argentina): "La hormiga escritora",

Si una hormiga resultara escritora, ¿qué podría escribir sino minificción?

88. Adolfo Bioy Casares: "Escribir"

Cada frase es un problema que la próxima frase plantea nuevamente.

92. Luisa Valenzuela (Argentina): “Confesión esdrújula”* Penélope nictálope, de noche tejo redes para atrapar un cíclope.

95. Augusto Monterroso (Guatemala-México): "Fecundidad"

Hoy me siento bien, un Balzac; estoy terminando esta línea.

97. Augustín Monsreal (México): "Cálculos renales"

¡Cuánto sufrí para poder arrojar la primera piedra!

98. Omar Lara (Chile): "Toque de queda"

-Quédate, le dije.

Y la toqué.

102. Eugenio Mandrini (Argentina): "Fiesta completa" $Y$ llovieron panes sobre el circo.

(Lagmanovich, 2006a: 71-78).

Más adelante volveremos sobre estos microrrelatos, pues lo que nos interesa ahora es alternar los comentarios planteados por Lagmanovich en relación con esta sección suya, de tal forma que podamos avanzar hacia el 
punto más crítico del microrrelato definido como texto narrativo.

\subsection{Planteamientos sobre los límites del texto narrativo en otros posibles microrrelatos más hiperbreves}

Así pues, en relación a la extrema brevedad, Lagmanovich comenta otro microrrelato no incluido en su corpus y titulado "Desinencia" (escrito por el español Juanjo Ibáñez), cuyo texto dice así: "Cuando estaba escribiendo el cuento más breve de su vida, la muerte escribió otro más breve todavía: ven”. Sobre la alusión en este microrrelato a otro no escrito y más hiperbreve, Lagmanovich se plantea cómo se podría escribir tal cosa, pues "si intentamos escribir tan sólo lo que presuntamente dijo la muerte, no tenemos un microrrelato, sino una orden expresada con una lexía aislada, por añadidura monosilábica; y no es así como se construye literatura" (2006a: 79). Bien, dejemos de lado la consideración de cómo se construye literatura, pues ya sabemos que su herramienta es la palabra, pero recordemos también que el arte contemporáneo ha apelado recurrentemente a la abstracción y al minimalismo, a lo conceptual y al contexto, a la deconstrucción y al silencio..., conformando así obras artísticas que cuestionan no solo las propias herramientas implicadas en sus respectivas artes, sino el arte mismo. En torno a esto, pensemos en pintura en la indagación del blanco sobre blanco de Malevich, pensemos en escultura en la mera recontextualización de un urinario en fuente de Duchamp, pensemos en música en el silencio de la pieza 4'33" de John Cage...

A continuación, Lagmanovich se pregunta si sería posible reducir aún más la extensión decreciente de los microrrelatos recopilados al final de su "sección C", en donde el último de estos, "Fiesta completa", consta de ocho palabras si se computa el necesario título (fundamental en estos casos), el cual lo incluye tentativamente apelando a "su carácter ingenioso y su recurrencia a la intertextualidad que evoca en el lector"10 (2006a: 79). Sin embargo, al haber concebido este último microtexto como microrrelato, Lagmanovich piensa en otro que también podría haber recopilado, escrito por el español José Costa Santiago, titulado “¡Sorpresa!”, y que dice así: “La

10. Presuponemos, por tanto, que Lagmanovich percibe aquí el desencadenamiento narrativo de tal situación ficcional expuesta. 
primera mañana después de mi muerte". Sobre este último, Lagmanovich comenta lo siguiente:

¿Un relato donde nada se relata, puesto que no existe forma verbal alguna que tome a su cargo la exposición del desarrollo de una acción? Cualquiera puede enhebrar unas cuantas formas nominales y dejarlas sobre el papel; pero, por mucho que las formas cambien, lo que el lector espera es - palabra más, palabra menos-lo que recibía del "cuento" el oyente de antaño: "Había una vez una viejecita que vivía en medio del bosque...". No es broma: es que hay que distinguir entre un relato y aquello que no lo es. Se puede innovar, pero no a costa de la narratividad (2006a: 79-80).

Según vemos, Lagmanovich entra en consideraciones ajenas al asunto crucial, sin abordar del todo lo que puede provocar, en última instancia, la narratividad de tales fenómenos microficcionales. En primer lugar, se observa cierta contradicción al principio de su comentario, ya que indica que un relato debe tener, al menos, un verbo explícito "que tome a su cargo la exposición del desarrollo de una acción". Si fuera esto así, no se explica entonces la denominación y concepción de microrrelato, además de su doble recopilación en su citado apartado y en su antología del género (cf. Lagmanovich, 2005: 95), del microtexto de Marco Denevi, en el cual no está explícito ningún verbo, al igual que sucede en el titulado "Sorpresa". Así pues, dejando a un lado el valor estético, la pregunta es la siguiente: ¿cuál es la diferencia entonces para considerar al microtexto de Denevi como microrrelato y dudar tanto, por ejemplo, del de José Costa?

\section{DEL MICRORRELATO COMO TEXTO NARRATIVO AL MICRORRELATO DE NARRATIVIDAD NO TEXTUAL}

A diferencia de tales interrogantes aludidos por Lagmanovich, nosotros pensamos que ambos microtextos son lo mismo: fenómenos microficcionales cuya narrativización completa está contenida en su elipsis, la cual requiere del lector para recomponer la situación ficcional presentada en mundo narrado. En ambos microtextos hay índices mínimos 
que contribuyen a narrativizar la situación (mundo) ficcional presentada. Así, por ejemplo, la asignación del título y la situación ficcional expuesta produce un nexo virtual que contribuye a desencadenarlo todo en motor de mundo narrado. En el microrrelato "Sorpresa", su intención ficcional narrativizadora se refleja por la inclusión de un título apropiado en colaboración con la selección precisa de una situación ficticia de potencial narratividad. El desencadenamiento de la secuencia narrativa sucede en la elipsis contendida entrambos, en ese salto y juego conceptual entre la indicación exclamativa del título, “SSorpresa!”, y la instalación sorpresiva, valga la redundancia, de tal situación ficcional presentada: «La primera mañana después de mi muerte», frase pensada o pronunciada por un personaje muerto. La sorpresa móvil no está solo en esta re-situación, sino en que tal hecho también se proyecta narrativamente sobre expectativas de lo que no se dice respecto al aludido mundo después de la vida, cuyo personaje-narrador, con su comunicada presencia, nos desvela el interrogante de que hay vida más allá de esta, pero sigue, como motor prospectivo narrativizador, manteniendo la incógnita en torno a tal sorpresa, lo que provoca también interrogantes sobre cómo (es aquello), qué (es lo que sucede), etc., en cuyo transmundo, o no-lugar aludido, el personaje está ya instalado, y en donde debe ocurrir u ocurrirá algo, o al menos ve o verá algo, o... Así pues, todo ello evidencia en el productor intenciones ficcionales narrativizadoras reflejadas en índices suficientes como para producir un mundo ficcional narrado, pero narrado de manera elíptica y cuya secuencia narrativa solo se completará de manera virtual y receptivamente, pues esta secuencia no aparece reflejada verbalmente en el texto. Además de esto, aquí podemos recurrir también a aquellos citados rasgos de índole pragmática y de intención, aludidos también para distinguir otros géneros como el poema en prosa o el aforismo (cf. Agudo y Jiménez, 2005: 13). En este aspecto, se evidencian las intenciones microficcionales de "Sorpresa" por lo dicho y también por su composición e inclusión deliberadas (tal como el titulado "Fiesta completa") para la antología española de microrrelatos Galería de hiperbreves (2001), cuya edición llevó a cabo el microrrelatista grupo célebre del Círculo Cultural Faroni (encabezado por el escritor español Luis Landero).

Así pues, por todo lo expuesto y explicado sobre el texto titulado "Sorpresa", nos hallamos, pues, ante un microrrelato, pero de textualidad no narrativa, ya que su intención productiva es la de generar movimiento 
narrativo a la estática situación ficcional presentada, cuya narración está elidida textualmente. Por tanto, se entenderá que aquella definición de microrrelato como texto narrativo no resulta válida para este caso ni para otros tantos semejantes, tal como, por ejemplo, el de Marco Denevi, cuyo texto, recordemos, Lagmanovich recopila como microrrelato, aunque tampoco contiene siquiera un verbo ${ }^{11}$. Y si esto es así, cabe preguntarse ¿por qué no le pareció este último tan objetable entonces como el de "Sorpresa"? Quizá una de las razones sea que en el de Marco Denevi se aprecian elididos los verbos que marcan las comas, pero sobre todo en el hecho de que este microtexto, al apoyarse completamente en lo intertextual, evoca mejor el desencadenamiento de una situación ficcional expuesta en todo un mundo de implicaciones narrativas. Así pues, gracias al apoyo intertextual del de Denevi, en el que el texto no es más que una mera exclamación situacional de la mujer de Putifar, se facilita o provoca mejor la proyección de todo un mundo ficcional narrado, el cual presupone en el lector unos cuadros o marcos de conocimiento en relación con esta historia presente en el Génesis, pero de resonancias arcaicas y material mítico greco-latino (cf. López, 1994). En todo caso, la intertextualidad no parece ser tampoco un recurso imprescindible para la creación proyectiva de un mundo ficcional narrado en su elipsis, sino un factor que contribuye a potenciar su evocación narrativizadora. Tampoco parece que todos los microrrelatos de muy pocas palabras exijan siempre la presencia siquiera de un verbo, si nos basamos en el de Denevi, en el de José Costa, o en el de otros tantos ejemplos posibles.

Ahora bien, sigamos avanzando. Si hemos visto que un microrrelato podría no tener siquiera un verbo (pues el verbo también puede estar elidido), y hemos visto que con muy pocas palabras se puede evocar (con o sin ayuda de la intertextualidad) todo un mundo ficcional narrado también en la elipsis, entonces, a la pregunta de Lagmanovich de si se podría producir algo más breve que aquellos y seguir siendo microrrelato, habría

11. En otro estudio publicado posteriormente, titulado El microrrelato hispanoamericano (2007), Lagmanovich recoge y analiza cuatro microrrelatos como ejemplos de hiperbrevedad de una y dos líneas, los cuales son los siguientes: "El dinosaurio" de Monterroso, "Justificación de la mujer de Putifar" de Denevi, "Fecundidad" de Monterroso y "Cuento de horror" de Arreola. Entre ellos, el de Denevi lo señala aquí con matices más objetables para poder concebirlo, desde su aludida postura narrativista, dentro de la clara y evidente categoría del microrrelato, ya que, a diferencia de "El dinosaurio" y de los otros dos — aunque estos dos también con ciertos matices señalados por Lagmanovich_- es el que prescinde de elementos de progresión temporal a través de su textualidad verbal (cf. Lagmanovich, 2007: 26-27). 
que sospechar que es posible. No obstante, el problema es que al reducir la situación ficcional expuesta con menos palabras, más compleja será plantear tal situación con intenciones narrativizadoras, conforme, pues, a provocar o evocar un mundo ficcional narrado en la elipsis (aparte de esto, otro de los problemas de tales microrrelatos de textualidad tan exigua o mínima podrá ser el de su relevancia estético-literarias).

\subsection{La narratividad invisible de los microrrelatos elípticos}

En cualquier caso, difícil no significa imposible, pues hace ya tiempo que tales planteamientos de elipsis extrema se han llevado a la praxis dentro del fenómeno productivo de la microficción contemporánea. Así pues, podemos destacar, entre otros, dos célebres microrrelatos elípticos de textualidad no narrativa y de claras intenciones ficcionales narrativizadoras, los cuales son semejantes a los ya comentados, en el sentido de que uno apela a la intertextualidad (histórica) y otro no (salvo a la visual). Ambos microtextos han sido citados y recopilados en antologías de microrrelato (cf. Obligado, 2009: 222 y 223), y ambos han sido escritos por dos microrrelatistas bien conscientes del fenómeno productivo de la microficción contemporánea. Nos referimos aquí al microrrelato titulado "Luis XIV", cuyo texto es el siguiente: "Yo», del español Juan Pedro Aparicio; y al titulado, pero sin texto, "El fantasma", del mexicano Guillermo Samperio. Respecto al de Aparicio, cuyo autor denomina a sus micorrelatos "cuánticos" (en alusión a la física cuántica), señalamos lo que él mismo comenta sobre su específico microrrelato elíptico y, en general, sobre su oportuna teoría del microrrelato-cuántico:

A esta materia oscura en literatura la llamamos elipsis. En ningún otro género o modo literario se deja sentir con tanta fuerza como en el cuántico. [...] Cuántico [...] tiene el valor significativo de referirse a un orden distinto de la física convencional, [...] y eso creo yo que le ocurre al micro, o perdón, al cuántico que está gobernado por leyes distintas de las que gobiernan las otras formas de la literatura. ¿Cuál es la ley del cuántico? Sin duda la elipsis. Algún exagerado dirá, claro, y el mejor de los cuánticos sería aquel que dejara la página en blanco. [...] Pero [...] 
habremos de aceptar que se necesita alguna palabra para cumplirlo, al menos una. Asi lo he propuesto en mi libro La mitad del diablo [2006] con el cuántico titulado "Luis XIV" [p. 163].

Se supone que los lectores [...] tienen la suficiente cultura como para saber que Luis XIV fue el llamado Rey Sol aquel que proclamó L'État c'est Moi. Siempre que he leido el relato a alguien he visto cómo provocaba una sonrisa. Ese "Yo" tiene para el lector la fuerza propia del monosílabo y la potencia de varios volúmenes de historia, una gran elipsis que abarca acontecimientos, intrigas, muertes, crímenes de estado [...].

En ese "Yo" hay, pues, movimiento. El que el lector culto le pone con su evocación (Aparicio 2008: 494-495 [la redonda es nuestra]).

Sin embargo, habría que puntualizar esto último, pues dicho microtexto no se apoya en una sola palabra (Yo), sino en su unión imprescindible con la/s del título ("Luis XIV"), ya que de lo contrario nada se movería en este microtexto que deviene en microrrelato en base a lo explicado por Aparicio, con cuyos argumentos coincidimos, pues percibimos bien, al igual que otros receptores, un movimiento narrativizador de una historia evocada gracias al apoyo intertextual. Estas intenciones narrativizadoras se inscriben en la selección deliberada de dos índices mínimos que procuran desencadenar movimiento al combinarse virtualmente entrambos (el nombre del título y el pronombre del texto). En este sentido, todo el microtexto es una prospección de un mundo ficcional narrado en su elipsis (cuya ficcionalidad se constata también en el sujeto enunciador de ese Yo, el cual no es el monarca histórico, sino el personaje histórico ficcionalizado por el contexto literario, tal como acontecería en una novela histórica). Por otra parte, se entenderá que, literal o verbalmente, este microtexto no es nada, pero en la medida en que todo aquello logra proyectarse receptivamente, entonces se actualiza tal microtexto en un destacable y meritorio microrrelato.

Respecto al de Guillermo Samperio, sin texto y titulado "El fantasma" (incluido en su Cuaderno imaginario, cuya obra obtuvo en México el Premio Nacional de Periodismo Literario al Mejor Libro de 
Cuentos, 1988), se podría señalar algo semejante al de Aparicio, aunque con matices. En este caso, al sustentarse tal fenómeno microficcional en una referencia visual explícita por un texto (hoja) en blanco, puede resultar más descriptiva y menos narrativa la propuesta de Samperio, pues al receptor puede no evocarle historia — ni, por tanto, narratividad — alguna, sino solo el guiño estático y metonímico de la invisibilidad aludida. Sin embargo, aquí hay que destacar también las evidentes intenciones narrativizadoras en la producción de la situación (mundo) ficcional presentada y las señales pragmáticas en las que se debe encuadrar tal fenómeno microficcional. Estos rasgos de índole intencional y pragmática no se pueden obviar para la clasificación de este microtexto como microrrelato o minificción, pues sabemos que el autor, tal como en el caso de Aparicio u otros, no ha pretendido producir exactamente un poema visual, un chiste o cualquier otra especie microtextual semejante, sino que su intención y propuesta literarias no ha sido otra que la de ofrecer el posible fenómeno microficcional más elíptico que se pudiera producir. Tampoco debemos olvidar aquí el hecho de que, en general, este tipo de propuestas microficcionales, de reducción máxima de palabras y consiguiente extrema elipsis, se inscriben dentro de la celebridad acaparada por "El dinosaurio"12. Y tampoco debemos olvidar que el fenómeno microficcional titulado "El fantasma" ha conseguido transmitir o evocar en receptores y/o antólogos de minificciones, tal como pretendió su autor, toda una historia: la historia mejor contada sobre un fantasma, o la historia más larga, o más breve, sobre un fantasma, dependiendo de la apelación receptiva a la enciclopedia de cada uno. Según señala el propio Samperio, "El fantasma" es "un relato muy largo, o [...] [el] más breve nunca escrito. Se llamará [...] «Fantasma» en una nueva edición. Claro que proviene de superar a mi maestro Monterroso, por [...] «El dinosaurio». [...] Busqué no solo la «microbrevedad», sino el texto significativo más breve" (cf. en la entrevista a Samperio realizada por Rafael Pontes Velasco, la cual fue incluida en su tesis doctoral, titulada La puerta de la cárcel está abierta. La poética de Guillermo Samperio ${ }^{13}$ [2011: 603] 2013:

12. Publicado en Obras completas (y otros cuentos) (1959), en cuyo libro de Monterroso aparece algún que otro microrrelato más, tal como, por ejemplo, el titulado "Vaca".

13. En torno a "El fantasma" de Samperio, remitimos al capítulo IV, titulado también "El fantasma", de tal tesis doctoral de Pontes, así como a su Apéndice de entrevistas a Samperio con alguna que otra referencia a esta microficción. Por otra parte, en relación con la minificción y la conciencia sobre este género en Samperio, remitimos a sus artículos escritos específicamente para los Congresos Internacionales de Minificción, tales como el II celebrado en Salamanca, España, 2002 (cf. Samperio, 2004: 65-69), y el IV realizado en Neuchâtel, 
599). Por tanto, desde tales perspectivas apuntadas, en donde los rasgos intencionales y pragmáticos son aquí muy evidentes, estaríamos, pues, ante la propuesta del fenómeno microficcional de extensión textual más reducida, especialmente en caso de suprimirle el artículo a "El fantasma", tal como propuso Samperio para futuras ediciones.

En relación con este tour de force por el infinito de la elipsis sobre el mínimo soporte textual narrativizador, Francisca Noguerol, en su tesis sobre Monterrroso ([1993] 1995: 46), ya señalaba la superación del modelo de "El dinosaurio", tanto por "El fantasma" como por el microrrelato titulado "Dios", del mexicano Sergio Golwartz, cuyo texto repite la misma palabra del título. Este microrrelato de Golwartz es el último de los 42 relatos incluidos en su libro Infundios ejemplares (1969), el cual tiene forma de embudo decreciente al ir reduciendo las palabras en cada uno de los textos (el primero consta de 500 palabras hasta llegar a este último de solo dos palabras iguales: "Dios": «Dios»). Lauro Zavala (2004: 97-98; 2006: 48) comenta todo esto y alude a una especial lectura del microrrelato de Golwartz dentro del contexto mexicano, país mayoritariamente católico. Por otra parte, sobre la elipsis contenida en "Dios", Zavala señalaba, en su artículo "El cuento ultracorto: hacia un nuevo canon literario" (1996), lo siguiente:

Una lectura literal [...], paradójicamente, puede llevar a reconocer lo que podría ser la narración más extensa del mundo. De hecho, su interpretación está en función directa delcapitalculturalydela enciclopedia intertextualqueposea cada lector, a la vez que permite efectuar simultáneamente lo que, siguiendo a Andrea Bell, podríamos llamar una lectura elíptica (resaltando sólo algunos episodios) o una lectura parabólica (de carácter metafórico y con final sorpresivo, necesariamente epifánico).

Sin duda, éste es uno de los [...] ultracortos con mayor densidad genérica y con mayor gradiente de polisemia en la narrativa contemporánea (1996: 76).

Como se ha visto, la definición del microrrelato como texto 
narrativo no resulta operativa para este tipo de evidentes producciones microficcionales. En estos casos, los rasgos e índices pragmáticos (contextuales) e intencionales colaboran también para determinar la particular ficcionalidad narrativizadora propuesta en tales microrrelatos o minificciones de máxima elipsis sin apenas soporte textual.

\section{PARTICULARIDADES DE LA NARRATIVIDAD MI- CROFICCIONAL A TRAVÉS DE EJEMPLOS DE MICRORRELA- TOS VISUALES Y PROTEICOS}

Dicho esto, acabamos de señalar los fenómenos microficcionales más complejos existentes, pues la elipsis está llevada a su absoluto en una supresión máxima del soporte literario que es la palabra, hasta el punto de que más allá de aquello está ya la hoja en blanco. Por otro lado, este tipo de formulaciones denotan también otro de los factores fundamentales del fenómeno productivo microficcional: su actitud experimentalista, transgresora, lúdica, irónica, etc. En este aspecto, y dentro también de la conciencia productiva microficcional, resultan abundantes y constantes las experimentaciones formales, visuales, lingüísticas, etc. Este factor proclive a la experimentación de toda índole en el fenómeno microficcional denota, en cierto modo, su herencia continuadora de las vanguardias históricas (y postvanguardias), y evidencia también su hermanamiento más próximo con la experimentación poética (caligramas, poesía visual, etc.). Entre las abundantes y diferentes propuestas de experimentaciones, frecuentemente lúdicas e irónicas, podemos señalar aquellas en donde lo destacado viene a ser lo visual en relación con lo textual. En torno a la posible problematicidad de su narratividad ficcional, dependerá no solo de la naturaleza narrativa, carácter elípitico y extensión textual, sino también podrá depender, tal como veremos más adelante, del formato, especie o categoría/forma literaria con la que pretenda metamorfosearse este tipo de formulaciones visuales o proteicas. Reproducimos solo algunos de los más conocidos y fáciles de transcribir (apuntando también los respectivos libros de los autores en donde aparecen sus microrrelatos):

Antonio Fernández Molina (España): "Las hormigas"

(... 442.413, 442.414, 442.415, 442.416

Cuando salió la primera hormiga no le 
442.417, 442.418, 442.419, 442.420

di importancia y creí que después de la 442.421, 442.422, 442.423, 442.424 excursión se habría quedado escondida 442.425, 442.426, 442.427, 442.428 debajo de la uña del dedo gordo del pie 442.429, 442.430, 442.431, 442.432 pero salió otra y otra. Hace tiempo 442.433, 442.434, 442.435, 442.436 que me ha desaparecido parte de la pier 442.437, 442.438, 442.439, 442.440 na. Comienza a nublárseme la vista, las 442.441, 442.442, 442.443, 442.444 hormigas siguen saliendo, sale otra $y$ $442.445 \ldots$ otra, otr...

[en Dentro de un embudo, 1973: 21]

$*$

Luisa Valenzuela (Argentina): "El sabor de una medialuna a las nueve de la mañana en un viejo café de barrio donde a los 97 años Rodolfo Mondolfo todavía se reúne con sus amigos los miércoles a la tarde"

-Qué bueno.

[en Aquí pasan cosas raras, 1975: 91]

$*$

Guillermo Cabrera Infante (Cuba): "Canción cubana"

¡Ay, José, así no se puede!

¡Ay, José, así no sé!

¡Ay, José, así no!

¡Ay, José, así!

¡Ay, José!

iAy!

[en Exorcismos de esti(l)o, 1976: 61] 
Hipólito G. Navarro (España): "Isósceles"

Interesa enriquecerse paulatinamente.

Enriquecerse paulatinamente interesa.

Paulatinamente Enriquecerse inTeresa.

[en Los últimos percances, 2005: 391]

$*$

Ana María Shua (Argentina): "Huyamos"

¡Huyamos, los cazadores de letras est'n aqu'!

[en Cazadores de letras. Minificción reunida, 2009: 368]

$*$

René Avilés Fabila (México): "Aviso en la jaula del ave Fénix"

Horario de los funerales y del nacimiento:

Cada cien años, aproximadamente a las 12:30 del día, se le prende fuego a la canela, el nardo y la mirra que conforman el nido del ave ("que es —según palabras de Ovidio-su propia cuna y el sepulcro de su padre”). A las 13:30, luego que las llamas aromáticas han cesado, el Fénix resurge triunfal, con su hermosísimo plumaje dorado y carmesí, de sus propias cenizas.

[en Fantasias en Carrusel, 1978: 90]

En estas seis microficciones se ejemplifica la importancia significativa de lo visual de diferentes maneras y en diferentes grados. Así, por ejemplo, en el microrrelato "Las hormigas", de Fernández Molina, observamos una combinación alternativa del texto con la serie de números correlativos, todo lo cual contribuye a "crear una ilusión óptica de una hilera de hormigas que van desfilando por el texto produciendo una sensación de mareo en el lector, equiparable a la que sufre el personaje 
literalmente devorado por ellas" (Andrés-Suárez, 2005: 96-97). En el caso de Luisa Valenzuela, el humor irónico del microrrelato se basa en invertir los índices del título y del texto, jugando así con las expectativas respecto a lo que debe ser el fenómeno paratextual frente al textual. En este aspecto, el lector capta inmediatamente el efecto visual de tales índices y aprecia también la dimensión desproporcionada del cuerpo sustancial del título frente al exiguo e insustancial texto. En realidad, el título es el auténtico texto del microrrelato (y viceversa). En el caso de "Canción Cubana", de Guillermo Cabrera, el efecto visual contribuye a reforzar el guiño y el humor del texto, en donde el significado de la primera oración varía según se va suprimiendo una palabra en cada frase sucesiva, y en donde, a la vez que se recurre a este artificio lipogramático de manera muy efectista, se juega también con los matices diferenciales y significativos de los acentos. En el microrrelato de Hipólito G. Navarro, la tríada de frases y palabras representan el aludido triángulo isósceles, cuya tercera y última frase, de connotaciones ajenas a la de las otras dos primeras de significados equivalentes, se visualiza bien por la acumulación de la letra mayúscula y por su desplazamiento, significativo y sorpresivo, dentro de la última palabra del texto: inTeresa. Respecto al microrrelato de Ana María Shua, el juego visual se sustenta en las mismas letras tipográficas, cuyo guiño humorístico se explicita en la desaparición (muerte) tipográfica de las letras por los temibles cazadores, cuyas letras parlantes son ya animales, o seres animados, huyendo en desbandada.

Por último, hemos dejado para el final el microrrelato de René Avilés Fabila, ya que con él se puede ejemplificar uno de los factores fundamentales y recurrentes de la microficción: su señalado carácter proteico en relación con infinidad de formas con las que el fenómeno microficcional se metamorfosea. En este caso, el microrrelato adopta la forma de una esquela, enmarcada incluso por su característico recuadro, tal y como así se destaca, por ejemplo, en la prensa periódica, aunque tal fantástica y humorística nota informativa se ubica aquí como "Aviso en la jaula del ave Fénix". En realidad, dicho recuadro no resulta necesario para que este microrrelato proteico se vea como esquela, pues su dimensión, referencias temporales, estilo, estructura y esquema del texto contribuyen ya a la mimetización perfecta con el modelo de esquela o aviso funerario cualquiera. 


\subsection{En torno a los microrrelatos proteicos en relación con su confusa narratividad}

Así pues, al igual que sucede en el microrrelato de Avilés Fabila, el fenómeno microficcional se ha revelado como el fenómeno literario más proteico existente, pues suele adoptar infinidad de formatos, categorías o géneros ajenos con cuyas múltiples formas se metamorfosea, mayormente para parodiar, ironizar, explorar o explotar recursos literarios en base a intenciones narrativizadoras de producción ficcional, y, generalmente, con particulares intereses creativos sorpresivos y desautomatizadores de lo establecido en relación con lo literario. Asimismo, junto al carácter proteico se suelen integrar otros recursos de apelación y completud receptiva, tales como aquellos de índole intertextual, ya que facilitan la reducción textual y, al mismo tiempo, favorecen la narrativización desencadenada en la elipsis que gobierna sobre la microficción, cuya menor apoyatura textual podrá exigir mayores estrategias y recursos compensatorios para compensar sus elípticos micro-universos literarios.

En relación con todo esto, Violeta Rojo (2009: 88) ha señalado la utilización constante de "cuadros" y, más concretamente, de "cuadros genéricos" para aportar más datos, los cuales no son tanto de contenidos, sino de esquemas narrativos. Tales "cuadros genéricos" actuarían como una especie de "cuadro intertextual de forma narrativa o de modo de relatar. Por ejemplo, en el minicuento se utilizan mucho las formas de la fábula, el bestiario, el mito, entonces podríamos pensar en un cuadro genérico de fábula, o en un cuadro genérico de mito" (Rojo, 2009: 88). Así pues, en el caso del microrrelato de Avilés Fabila, su "cuadro genérico" no es el del mito del Ave Fénix, sino el de la esquela, en donde, a su vez, se recurre a la intertextualidad del mito aludido. Por otra parte, Violeta Rojo recopila en su fundamental monografía, procedente de su tesis doctoral (cf. Rojo, [1993] 2009: 97-142), cuarenta y cinco ejemplos variados en los que se aprecia parte de la diversidad proteica representada por la microficción. $\mathrm{Al}$ respecto del carácter proteico e intertextual del fenómeno, Rojo señala que, por ejemplo:

podemos encontrar algunos de apariencia de ensayos, o de reflexión sobre la literatura y el lenguaje, recuerdos, anécdotas, listas de lugares comunes, de términos para 
designar un objeto, fragmentos biográficos, fábulas, palíndromos, definiciones a la manera de diccionario, reconstrucciones falsas de la mitología griega, instrucciones, descripciones geográficas desde puntos de vista no tradicionales, reseñas de falsos inventos... (Rojo, 2009: 79).

Asimismo, en relación con la tendencia de la microficción a parodiar todo tipo de géneros, Rojo destaca algunas de las categorías cortas de la que se ha valido y se suele valer dicho fenómeno, tales como, por ejemplo,

los llamados géneros gnómicos [...]: el aforismo [...]; la alegoría [...]; la anécdota [...]; el caso [...]; el chiste [...]; el ejemplo [...]; la fábula o apólogo [...]; la ocurrencia [...]; la parábola [...]; el proverbio, la sentencia, el adagio y el refrán... [...] todas estas formas de las que a menudo se nutre el minicuento están relacionadas con la moral, pero como podemos observar en los ejemplos de la Antología, ningún minicuento basado en estas formas termina conteniendo enseñanzas morales y sí todo lo contrario. Estos textos se han parodiado, su sentido ha sido desviado mediante un proceso de transformación. La transformación convierte la seriedad en humor, y el sentido moral en un pragmatismo a veces cínico e irreverente (Rojo, 2009: 92).

En torno a todo esto, remitimos ahora a algunos de los microrrelatos que transcribimos y recogimos de la aludida "sección C" de Lagmanovich. Tal como se podrá comprobar, algunas de aquellas microficciones se asemejan a la variada tipología discursiva de categorías/formas cortas mencionadas, aunque en todas ellas destaca la inclusión de un título como índice ubicador y resemantizador apropiado y explotado para sus propias intenciones de producción microficcional, en donde se reflejan también sus rasgos paródicos (respecto a tales formas cortas) y/o irónicos (referenciales). Así pues, aunque el fenómeno microficcional moderno/ contemporáneo pueda adoptar los "cuadros genéricos" de estas formas cortas, esto no significa en absoluto que sea estas mismas formas cortas, ya que las intenciones productivas microficcionales son bien distintas 
y diferenciales respecto a la función clásica y caracterizadora de tales categorías/formas cortas arcaicas o tradicionales. Hay, pues, un abismo semántico e intencional entre la producción distintiva de la microficción moderna/contemporánea y la producción clásica o tradicional de máximas, apotegmas, aforismos, sentencias, fábulas, etc.

\subsection{La progresiva delimitación del microrrelato como texto más narrativo y su problemática con ciertas formulaciones proteicas de narratividad compleja}

En relación con este tipo de microrrelatos o minificciones, vamos a recopilar ahora el microtexto titulado "Euclideana", del mexicano René Avilés Fabila, cuya microficción fue recopilada por Zavala en su antología La minificción en México. 50 textos breves (2002: 34), así como también fue recogida por Lagmanovich en su sección (B) de "microrrelatos de una o dos líneas" (2006a: 61). La microficción es la siguiente:

\section{Euclideana}

En una ciudad actual la distancia más corta entre dos puntos no es la recta: es el zigzag que nos evita los semáforos.

René Avilés Fabila [en Fantasías en carrusel (1969-1994), 1995: 396]

Ahora bien, esta producción, según David Roas, "es un aforismo, un pensamiento, una reflexión ingeniosa, es decir, una de las muchas manifestaciones de la categoría de los microtextos, pero en él no se narra historia alguna, no hay tensión narrativa. No es un microrrelato" (2010: 26). En este sentido, se refleja aquí cierta perspectiva del microrrelato reasumido ya como texto claramente narrativo y como especie de cuento en miniatura, seguramente por la señalada delimitación excesiva que ha ido progresando, especialmente en España, desde asunciones teóricas cada vez más narrativistas sobre un fenómeno genérico de particular narratividad más compleja, diversa, amplia y enriquecedora, según nosotros, que la reductiva y unidireccional demarcación narrativa allí pretendida. Alrededor, pues, de tal concepción del microrrelato como texto narrativo, se ha defendido (Lagmanovich, 2006b; Andrés-Suárez, 2007; Valls, 2008, etc.) y se ha negado (Roas, 2010; Felices, 2010) el estatuto 
genérico autónomo del microrrelato, cuyas perspectivas narrativistas obligan a una cuestionable exclusión —o a una problemática argumentación inclusiva - de los fenómenos propiamente microficcionales de naturaleza textual no narrativa, o de narratividad más difusa, compleja o híbrida. Por otro lado, a diferencia de David Roas, quien, tal como hemos visto, excluye claramente aquel fenómeno microficcional por no adecuarse a su concepción restrictiva del microrrelato puramente narrativo, nosotros, sin embargo, consideramos tal producción de Avilés Fabila como un claro exponente del fenómeno microficcional, es decir, no es otra cosa que un microrrelato o minificción de estructura proteica proposicional, cuya proyección de su historia se relaciona en parte con lo que Violeta Rojo, readaptando ciertos postulados de Tomachevski (1982: 182) y de Kayser (1976: 98), define como "minicuentos que son narraciones incompletas, o sin fábula aparente" (Rojo, 2009: 51). En este sentido, la ficcionalidad narrativizadora del microrrelato de Avilés Fabila acontece de una manera simultánea y proyectiva, la cual implica planos superpuestos de lectura en donde, en última instancia, se alude a nuestra propia historia dentro del contexto actual de saturación urbana y problemáticos desplazamientos (en automóviles), lo cual nos obliga a sortear semáforos (o impedimentos) para llegar antes, o a tiempo, al destino marcado: toda una pequeña odisea cotidiana. Por otra parte, el microrrelato se formula como una resolución irónica al problema planteado, cuya producción microficcional conlleva todo lo indicado más arriba, ya denotado desde la intencionalidad ficcional del título intertextual e irónico respecto a la Geometría de Euclides. Esta intencionalidad ficcional impregna la producción de arriba abajo, conformada dentro de los códigos microficcionales constitutivos a través de la marcación significativa del índice del título en combinación con el cuerpo y estructura del índice del texto, el cual adopta "el cuadro genérico" de contra-proposición de la geometría euclidiana, según la cual la distancia más corta entre dos puntos sería la recta. La falsificadora reformulación proposicional de Avilés Fabila, de claras intenciones ficcionales, parodia tal proposición (o axioma popular) derivada de la geometría euclidiana, y la desmiente irónicamente en torno a la problemática movilidad urbana. La artimaña ficcional de la pseudo-proposición se fundamenta aquí en el juego polisémico de las palabras "distancia más corta", en donde se superponen dos magnitudes distintas: el Espacio (geométrico euclidiano) y el Tiempo. En este sentido, la distancia más corta se logra en el paradójico 
zigzag que acorta la distancia... temporal. Asimismo, la lectura irónica del texto conlleva implícito un plano epistemológico clásico, el cual es contrapuesto a otro moderno o contemporáneo, desde donde se apela a nuestra experiencia urbana. Es decir, se contrapone lo clásico, lo puro, la certeza de la geometría euclidiana, la cómoda y recta verdad categórica de la abstracción, la gravedad proposicional, etc., frente a lo (post-)moderno, lo híbrido, la relatividad del espacio/tiempo (urbano), la incómoda y retorcida verdad irónica de la materialización, la parodia proposicional... Por otro lado, la específica creación autónoma del microtexto refleja su intención productiva y sus recursos ficcionales manejados: composición estructural y constitutiva del título y texto, intertextualidad, reescritura y parodia, densidad semántica contenida en la elipsis y necesidad de marcos de conocimientos para desentrañar el significado total y el carácter proteico, irónico, ficcional y alusivo del microtexto, elaboración productiva ficcional proyectada hacia un final que pretende la sorpresa sustentada por la paradoja, etc. Así pues, esta composición creacional autónoma, bien deliberada e intencional (referencias del autor, contexto de publicación original del microrrelato, etc.), conlleva evidentes índices proyectados hacia una dirección ficcional muy determinada. En suma, no observamos en "Euclideana" pretensiones creacionales de ser cualquier cosa discursiva indeterminada ("un aforismo, un pensamiento, una mera reflexión ingeniosa..."), sino que en toda su composición vemos reflejado el código productivo e intencional del microrrelato o minificción.

En torno a todo esto, no está de más recordar, finalmente, lo señalado al respecto por Dolores Koch (2002):

[El microrrelato] demuestra ciertos elementos de anarquía intelectual y espiritual. Primeramente, juega irreverentemente con las tradiciones establecidas por la preceptiva al escaparse de las clasificaciones genéricas, y se complace en romper las barreras entre cuento, ensayo y poema en prosa. Juega con la literatura misma en sus alusiones y reversiones. Juega con actitudes aceptadas mecánicamente ofreciendo o redescubriendo perspectivas. Juega con el concepto de la realidad, la desproporción y la paradoja. Su autor se vale de variados recursos narrativos, y sorprende al lector con un despliegue de ideas, de 
palabras, o un punto de vista insospechado (texto citado y recogido de Noguerol, 2011: 608).

\section{REFERENCIAS BIBLIOGRÁFICAS}

AGUDO M. y JIMÉNEZ ARRIBAS, C. (eds.) (2005). Campo Abierto. Antología del poema en prosa en España (1990-2005). Barcelona: DVD ediciones.

ÁLAMO FELICES, F. (2010). "El microrrelato. Análisis, conformación y función de sus categorías narrativas". Signa. Revista de la Asociación Española de Semiótica 19, 161-180 (también en http://www.cervantesvirtual.com/portales/signa/catalogo_titulos/ [20/05/2017]).

ANDRÉS-SUÁREZ, I. (2005). "Del microrrelato surrealista al transgenérico (Antonio Fernández Molina y Julia Otxoa)". En Asedios a una nueva categoría textual: el microrrelato, A. Cáceres Milnes y E. Morales Piña (eds.), 83-110. Valparaíso: Universidad de Playa Ancha.

(2007). "El microrrelato: caracterización y limitación del género". En Mundos mínimos. El microrrelato en la literatura española contemporánea, T. Gómez Trueba (ed.), 11-39. Gijón: Cátedra Miguel Delibes-Llibros del Pexe.

(2008). "Prólogo". En La era de la brevedad. El microrrelato hispánico, I. Andrés-Suárez y A. Rivas (eds.), 11-21. Palencia: Menoscuarto Ediciones.

APARICIO, J. P. (2008). "Poética cuántica". En La era de la brevedad. El microrrelato hispánico, I. Andrés-Suárez y A. Rivas, 491-495. Palencia: Menocuarto Ediciones.

CÍRCULO CULTURAL FARONI (ed.) (2001). Galería de hiperbreves. Nuevos relatos mínimos. Barcelona: Tusquets Editores.

EPPLE, J. A. (ed.) (1999). Brevísima relación. Nueva antología del microcuento hispanoamericano. Santiago de Chile: Mosquito Editores.

GARRIDO DOMÍNGUEZ, A. (1993). El texto narrativo. Madrid: Editorial Síntesis.

KAYSER, W. (1976). Interpretación y análisis de la obra literaria. 
Madrid: Gredos.

KOCH, M. D. (1981). "El micro-relato en México: Torri, Arreola, Monterroso y Avilés Fabila". Hispamérica X/30, 123-130.

(1986). "El micro-relato en la Argentina: Borges, Cortázar y Denevi".

Enlace literario: Revista de literatura en lengua española (Nueva York) 5/6, 9-13.

(2002). "Algunas ideas sobre la microficción". Revista digital Literatura.com (cf. sumario en http://axxon.com.ar/not/c110InfoLiteraturacom.htm [10-03-2017]).

LAGMANOVICH, D. (Ed.) (2005). La otra mirada. Antología del microrrelato hispánico. Palencia: Menoscuarto Ediciones.

(2006a). El microrrelato. Teoría e historia. Palencia: Menoscuarto Ediciones.

(2006b). "La extrema brevedad: microrrelatos de una y dos líneas". Espéculo. Revista de estudios literarios (Universidad Complutense de Madrid), 32 (en https://pendientedemigracion.ucm.es/info/ especulo/numero32/exbreve.html [10-07-2017]).

(2007). El microrrelato hispanoamericano. Bogotá: Universidad Pedagógica Nacional.

LEAL, L. (1971). Historia del cuento hispanoamericano. México, D. F.: Ediciones de Andrea.

LÓPEZ SALVÁ, M. (1994). "El tema de Putifar en la literatura arcaica y clásica griega en su relación con el Próximo Oriente”. Cuadernos de Filología Clásica. Estudios griegos e indoeuropeos (Universidad Complutense de Madrid) 4 (en http://revistas.ucm.es/index.php/ CFCG/article/view/CFCG9494110077A [10-07-2017]).

NOGUEROL JIMÉNEZ, F. (2000). La trampa en la sonrisa: sátira en la narrativa de Augusto Monterroso. Sevilla: Universidad de Sevilla. (2011). “Juego de villanos: para una poética de la seducción”. En $A$ través de la vanguardia hispanoamericana: origenes, desarrollos, transformaciones, M. Fuentes y P. Tovar, 603-615. Tarragona: URV.

OBLIGADO, C. (ed.) (2009). Por favor, sea breve 2. Madrid: Páginas de Espuma.

PONTES VELASCO, R. (2013). La puerta de la cárcel está abierta. La poética de Guillermo Samperio. Salamanca: Ediciones Universidad de Salamanca (cf. tesis de 2011 en http://hdl.handle. 
net/10366/115599 [10-07-2017]).

ROAS, D. (2010). "Sobre la esquiva naturaleza del microrrelato". En Poéticas del microrrelato, D. Roas (comp.), 9-42. Madrid: Arco Libros.

RÓDENAS DE MOYA, D. (2007). "Consideraciones sobre la estética de lo mínimo". En Mundos mínimos. El microrrelato en la literatura española contemporánea, T. Gómez Trueba (ed.), 67-93. Gijón: Cátedra Miguel Delibes-Llibros del Pexe.

ROJO, V. (2009). Breve manual (ampliado) para reconocer minicuentos. Caracas: Editorial Equinoccio.

SAMPERIO, G. (1988). Cuaderno imaginario. México, D. F.: Editorial Diana.

(2004). "La ficción breve". En Escritos disconformes. Nuevos modelos de Lectura, F. Noguerol Jiménez (ed.), 65-69. Salamanca: Ediciones Universidad de Salamanca.

(2008). "El halcón de la ficción breve lee páginas clásicas". En La era de la brevedad. El microrrelato hispánico, I. Andrés-Suárez y A. Rivas (eds.), 569-580. Palencia: Menoscuarto Ediciones.

TOMACHEVSKI, B. (1982). Teoría de la literatura. Madrid: Akal.

VALADÉS, E. (Dir.). El Cuento. Revista de la imaginación, 1964-1999 (en http://www.elcuentorevistadeimaginacion.org/indexcuento. php [10-07-2017]).

VALLS, F. (2008). Soplando vidrio y otros estudios sobre el microrrelato español. Madrid: Páginas de Espuma.

ZAVALA, L. (1996). "El cuento ultracorto: hacia un nuevo canon literario". Revista Interamericana de Bibliografía XLVI.1-4, 6778 (también en http://www.educoas.org/portal/bdigital/contenido/ rib/rib_1996/index.aspx [10-07-2017]). (2002) (ed.). La minificción en México. 50 textos breves. Bogotá: Universidad Pedagógica Nacional.

(2004). Cartografías del cuento y la minificción. Sevilla: Editorial Renacimiento.

(2006). La minificción bajo el microscopio. México, D. F.: UNAM.

Recibido el 31 de mayo de 2017.

Aceptado el 18 de junio de 2017. 